\title{
Paresia de IV nervo por diabete melito
}

\author{
IV nerve palsy due to diabetes mellitus
}

Renato L. N. Curi ${ }^{(1)}$

\begin{tabular}{|c|}
\hline RESUMO \\
\hline Devido à raridade do fato, o autor apresenta 2 casos de paralisia \\
de IV nervo, secundários a diabete melito em jovens. Apesar de casos \\
de paralisias de III e VI nervos geralmente evoluírem para a recupe- \\
ração espontânea, nossos casos de paralisia de IV evoluíram para a \\
descompensação com hiperação secundária de oblíquo inferior, o que \\
levou à cirurgia, com excelentes resultados. \\
Palavras-chave: Diabete melito; Paresia IV nervo (tratamento cirúrgico).
\end{tabular}

Palavras-chave: Diabete melito; Paresia IV nervo (tratamento cirúrgico).

\section{INTRODUÇÃO}

Dentre as causas gerais de paresias oculomotoras, o diabete melito é sempre citado. Como causa de paresia de III e de VI nervos, sabemos ser, de fato, extremamente freqüente. Entretanto, apesar de constar de todos os textos clássicos como agente etiológico da paresia do IV nervo, o diabete melito muito raramente é observado e, devido a isso pouco se conhece a respeito do quadro.

Há muito tempo trabalhando com distúrbios oculomotores, apenas em duas ocasiões pudemos observar a paresia de oblíquo superior devida a diabete, ambos os casos surgindo e evoluindo de modo semelhante.

A raridade e as características clínicas levaram-nos a observar esses casos, chamando a atenção para a possibilidade da etiologia citada e sua busca como agente possível na paresia do IV nervo.

\section{CASOS CLÍNICOS}

a) WLS, 23 anos, brasileiro, branco, solteiro, estudante de medicina, procurou-nos devido a surgimento de diplopia de modo agudo, que o levava a adquirir torcicolo com a cabeça pendida sobre o ombro, o que melhorava seu quadro sintomático.

Ao exame oftalmológico, o quadro motor apresentado era típico de paresia unilateral de oblíquo superior, com déficit desse músculo e pequena hiperação de oblíquo inferior homolateral (Figura 1). Não apresentava qualquer outra alteração ao exame oftalmológico, a não ser aquelas ligadas à paresia, inclusive com grande exciclotorção observada ao exame do fundo de olho.

Pesquisa etiológica foi desenvolvida abrangendo as causas possíveis relacionadas ao quadro, mesmo porque o paciente, apesar de estudante de medicina, não relatava qualquer doença que pudesse relacionar-se ao quadro.

Dentre os exames realizados, para surpresa inclusive do paciente, a glicemia mostrava $380 \mathrm{mg} / \mathrm{ml}$. O paciente foi encaminhado ao Serviço de
Professor Titular de Oftalmologia da Universidade Federal Fluminense - UFF. Chefe do Serviço de Oftalmologia do Hospital Universitário Antonio Pedro-UFF

ndereço para correspondência: Prof. Dr. Renato L.N.Curi. Rua Tupinambás, 142. São Francisco, Niterói (RJ) CEP 24360-270. 


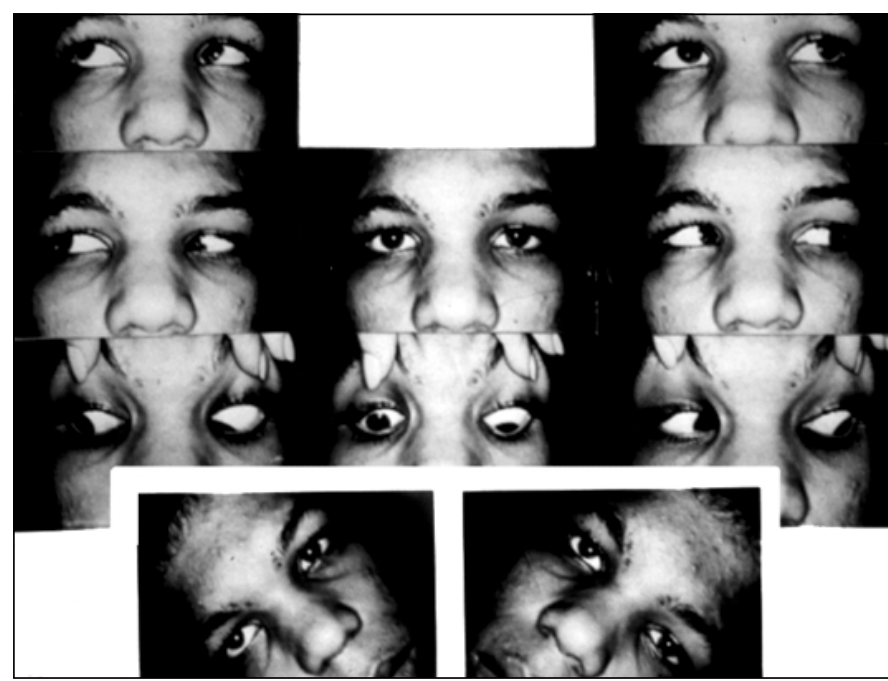

Fig. 1 - Paresia do músculo oblíquo superior direito(OSD) com discreta hiperação do músculo oblíquo inferior direito (OID). Teste de Bielschowsky positivo com a cabeça virada sobre o ombro direito.

Endocrinologia, continuando, a partir de então, tratamento clínico da doença.

Controle trimestral foi realizado durante 2 anos, não havendo melhora do quadro oculomotor, quando o paciente foi submetido à correção cirúrgica, com recuo do músculo oblíquo inferior (OI), tendo boa resposta, melhorando intensamente o torcicolo e estabilizando o quadro.

b) RMA, 15 anos, branco, brasileiro, estudante, diabético insulino-dependente, compareceu à consulta encaminhado por colegas (endocrinologista e oftalmologista), com quadro de paresia de IV nervo unilateral, surgido há 1 mês, após hiperglicemia que atingiu $460 \mathrm{mg} / \mathrm{ml}$. Controlado o diabete o quadro se mantinha.

Ao exame oftalmológico, nenhuma alteração foi observa$\mathrm{da}$, a não ser o quadro oculomotor, em todo semelhante ao primeiro caso. A etiologia diabética nesse caso era evidente, porém, mesmo assim, o paciente foi encaminhado ao neurologista tendo completado bateria de exames buscando outras causas, que foram afastadas.

Devido ao pouco tempo de aparição do quadro, optamos por conduta expectante, como é obrigatório em todas as paresias recentes. Durante 1 ano não houve qualquer regressão no quadro; muito pelo contrário, a hiperação de oblíquo inferior aumentou progressivamente, piorando o quadro do torcicolo torcional apresentado pelo paciente (Figura 2).

Após esse prazo, foi submetido à miectomia do oblíquo inferior, com boa recuperação funcional (Figura 3).

\section{DISCUSSÃO}

A apresentação desses casos nos faz lembrar de que o diabete é causa comum de paresias oculomotoras, principalmente de III e VI nervos crânicos. Esses casos apresentam

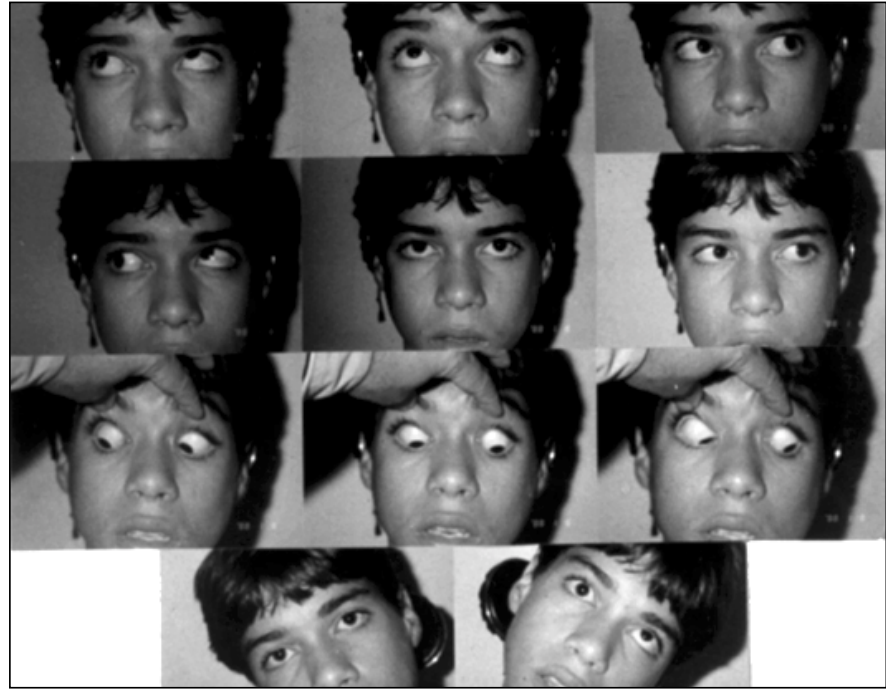

Fig. 2 - Paresia do músculo oblíquo superior esquerdo (OSE) com grande hiperação do músculo oblíquo inferioresquerdo(OIE).Testede Bielschowsky positivo com a cabeça virada sobre o ombro esquerdo. Pré operatório.

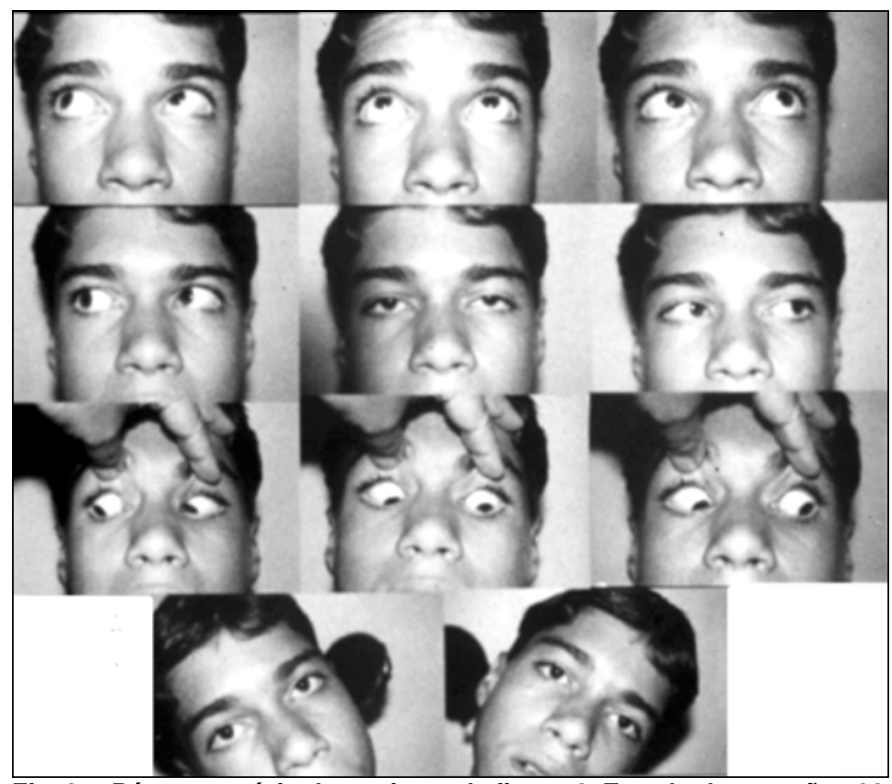

Fig. 3 - Pós-operatório do paciente da figura 2. Estudo das versões 60 dias após miectomia com cauterização do músculo oblíquo inferior esquerdo (OIE).

freqüentemente características clínicas bem definidas, quais sejam: freqüente surgimento da paresia acompanhada de dor ocular, paresia brusca, relacionada ou não com o nível da glicemia nesse momento, com características conhecidas de paresia de etiologia vascular e, o que é a regra, com regressão espontânea com o tempo e o bom controle da doença.

Berlit (1978) ' , estudando 412 oftalmoplegias, observou 172 de III nervo, 165 de VI nervo e apenas 25 de IV nervo, sendo que em 135 dessas, hipertensão arterial e diabete estavam presentes, sem definir em que nervos especificamente. 
Rush \& Younge $(1981)^{2}$ estudaram série de 1000 paralisias oculomotoras, quanto à causa e à recuperação. A freqüência das paralisias de III, IV e VI nervos não diferem das estatísticas gerais, sendo a de IV a menos freqüente. Quanto à causa, nesse estudo, 263 pacientes não tiveram as etiologias definidas, apesar dos exames complementares realizados. Ao mesmo tempo, em grupo de 127 pacientes orientados para diagnóstico, só 10 tiveram sua etiologia definida e $51 \%$ destes evoluíram para a remissão espontânea. De todos os pacientes estudados, $48 \%$ reverteram seus quadros. Dentre as oftalmoplegias devidas a doenças vasculares como diabete e hipertensão arterial, $71 \%$ tiveram quadros temporários, enquanto que naquelas devidas a trauma, tumores ou aneurismas praticamente não houve recuperação.

Metz $(1986)^{3}$ considera o diabete como causa de paralisia de IV nervo, apesar de afirmar que o trauma é sem dúvida sua causa mais freqüente. Ao lado disto, aponta ser também essa a causa mais freqüente de diplopia vertical.

Glaser \& Bachynsky (1990) ${ }^{4}$ citam o diabete como causa relativamente freqüente de paralisia de IV nervo em pacientes idosos, sendo rara em jovens. Citam, ao lado disso a freqüente associação de nervos crânicos paréticos, o que, quando presente deve-se isolar o diabete, pois esta doença causa mononeurites.

Lazzaroni et al (1993) ${ }^{5}$ estudaram 44 pacientes diabéticos com paralisias oculomotoras, demonstrando que o VI nervo foi acometido em $55 \%$ dos casos, o III em $39 \%$ e o IV em apenas 6\%. Em 19 pacientes a paralisia levou à identificação do diabete; em 25, ocorreu em pacientes diabéticos a 9,2 anos, com desvio padrão de 6,2 anos. As oftalmoplegias reverteram em média de 93 dias (156/39 dias). Não foi encontrada correlação entre a paralisia oculomotora e o controle glicêmico, a função renal, a presença de retinopatia diabética ou outra complicação neurológica.

Newman (1994) ${ }^{6}$ relata ser a alteração microvascular, produzida por doenças tais como hipertensão arterial, diabete e colagenoses, a causa básica de paresia de IV nervo em pacientes de idade avançada, o que não seria comum em jovens.

Com relação aos dois quadros apresentados, em ambos o aparecimento relacionou-se à hiperglicemia acentuada, no primeiro caso desconhecida pelo paciente, sendo primeiro sinal da doença; e, no segundo, caracterizada em exames de avaliação rotineiros realizados por diabetólogo. Ao lado desse fato, em ambos os casos a evolução deu-se de modo paulatino, piorando progressivamente, principalmente pelo desenvolvimento de hiperfunção de oblíquo inferior.

Fato a ser considerado foi o total desconhecimento por parte dos diabetólogos e neurologistas, ligados aos pacientes, da possibilidade de a etiologia da paresia do IV nervo ser devida ao diabete. Em todo o tempo em que nos relacionamos com esses profissionais, sempre nos foi dito que nunca qualquer deles tinha visto quadros semelhantes e que não tinham qualquer experiência no tratamento desses quadros. Inclusive, apesar de a equipe ser muito experiente no tratamento do diabete, esses são os 2 casos por ela conhecidos, pois participaram com nossa equipe do tratamento de ambos os pacientes.

Por fim, deve-se chamar a atenção para a evolução dos quadros que, apesar do controle eficaz do diabete, em ambos os pacientes, só mostraram melhoras com o tratamento cirúrgico, fato raro nas paresias diabéticas de III e VI nervos.

\section{SUMMARY}

Due to its rarety the author, present 2 cases of IV nerve palsy secondary to diabetes mellitus in young patients. Although cases of III and VI nerve palsy often recover to spontaneously, our patients with IV nerve palsy developed secondary inferior oblique hyperaction, and were submitted to surgical procedure with good results.

Keywords: Diabetes mellitus; IV nerve palsy (surgical treatment).

\section{REFERÊNCIAS BIBLIOGRÁFICAS}

1. Berlit P. Isolated and combined pareses of cranial nerves III, IV and VI. A retrospective study of 412 patients. J Neurol Sci 1991;103(1):10-5.

2. Rush JA, Younge BR. Paralysis of cranial nerves III, IV and VI. Causes and prognosis in 1000 cases. Arch Ophthalmol 1981;99(1):76-9.

3. Metz H. Think superior oblique palsy. J Pediatr Ophthalmol Strabismus 1986; 23(4):166-9.

4. Glaser JS, Bachynski B. Infranuclear disorders of eye movement. In: Glaser JS. Neuro-Ophthalmology, 2nd ed. Philadelphia: J.B.Lippincott, 1990; capítulo 12 .

5. Lazzaroni F, Laffi GL, Galuppi V, Scorolli L. Paralysies des nerfs oculomoteurs au cours du diabete. Etude retrospective de 44 cas. Rev Neurol Paris 1993;149(10):571-3.

6. Newman SA. Disorders of ocular motility. In: Slamovits TL, Burde R. NeuroOphthalmology. Textbook of Ophthalmology ed Podos SM Yannof M. vol 6, Mosby Yearbook Europe, 1994; capítulo 7

\section{Novidades na Internet:!:}

Agora no site CBO você tem disponível todas as informações na íntegra dos

Arquivos Brasileiros de Ditalmologia

http://w w w.cbo.com.br/abo 